\title{
An Endophytic Nodulisporium sp. Producing Volatile Organic Compounds Having Bioactivity and Fuel Potential
}

\author{
Morgan Tess Mends ${ }^{1 \#}$, Eizadora Yü ${ }^{2 *}$, Gary A Strobel ${ }^{1 *}$, Syed Riyaz-UI-Hassan1 ${ }^{+}$, Eric Booth ${ }^{1}$, Brad Geary ${ }^{3}$, Joe Sears ${ }^{4}$, Craig A Taatjes $^{5}$ and
} Masood Z Hadi2,6

${ }^{1}$ Department of Plant Sciences, Montana State University, Bozeman, Montana, 59717, USA

${ }^{2}$ Biomass Conversion Technologies, Sandia National Laboratories, Livermore, California, 94551, USA

${ }^{3}$ Department of Plant and Wildlife Sciences, Brigham Young University, Provo, Utah, 84602, USA

${ }^{4}$ Center for Lab Services/RJ Lee Group, 2710 North 20th Ave., Pasco, Washington, 99301, USA

${ }^{5}$ Combustion Research Facility, Sandia National Laboratories, Livermore, California, 94551, USA

${ }^{6}$ Joint BioEnergy Institute, Emeryville, California, 94608, USA

"These authors contributed equally to the work completed on this project

${ }^{+}$Microbial Biotechnology Division, Indian Institute of Integrative Medicine (CSIR), Canal Road, Jammu-180 001, India

\begin{abstract}
Nodulisporium sp. has been isolated as an endophyte of Myroxylon balsamum found in the upper Napo region of the Ecuadorian Amazon. This organism produces volatile organic compounds (VOCs) that have both fuel and biological potential. Under microaerophilic growth environments, the organism produces 1, 4-cyclohexadiene, 1-methyl- , 1-4 pentadiene and cyclohexene, 1-methyl-4-(1-methylethenyl)- along with some alcohols and terpenoids of interest as potential fuels. The fungus was scaled up in an aerated large fermentation flask, and the VOCs trapped by Carbotrap technology and analyzed by headspace solid -phase microextraction (SPME) fiber-GC/MS. Under these conditions, Nodulisporium sp. produces a series of alkyl alcohols starting with 1-butanol-3-methyl, 1propanol-2-methyl, 1- pentanol, 1-hexanol, 1-heptanol, 1- octanol, 1-nonanol along with phenylethyl alcohol. The organism also produces secondary alkyl alcohols, esters, ketones, benzene derivatives, a few terpenoids, and some hydrocarbons. It appears that many of the products have fuel potential. Furthermore, the VOCs of Nodulisporium sp. were active against a number of pathogens causing death to both Aspergillus fumigatus and Rhizoctonia solani and severe growth inhibition produced in Phytophthora cinnamomi and Sclerotinia sclerotiorum within $48 \mathrm{hr}$ of exposure. The Carbotrapped materials somewhat mimicked the bioactivities of the culture itself when certain test organisms were exposed to these VOCs. A brief discussion on the relationship of these fungal VOCs to those compounds found in transportation fuels is presented.
\end{abstract}

Keywords: Terpenes; rDNA; Endophyte; VOCs; Carbotraps; Mycodiesel $^{\mathrm{m}}$

\section{Introduction}

Endophytic microorganisms are found throughout nature as they inhabit the interstitial spaces of plant tissues and cause no apparent symptoms of their presence in the plant [1]. The vastness of the plant kingdom is only outweighed by the sheer number and diversity of the microbial flora existing in these niches. It is also worthy to note that finding taxonomic novelty among organisms living in this biological niche is extremely likely [2].

Apparently, the relationship existing between the microbe and the plant can vary from symbiotic to borderline pathogenic [3]. While the endophyte needs nutritive sources offered by the host plant, its contribution to the interaction may be one of tissue protection generated by virtue of its own anti-pest metabolites. In fact, numerous antibiotics, including antimycotics, insecticides, and antiviral compounds have been isolated from various endophytic microbes $[3,4]$.

More recently, a novel endophytic fungus has been described and named Muscodor sp. [5]. To date, all members of this genus produce volatile, biologically active molecules that have adverse effects on other fungi, bacteria, and insects [5,6-8]. Because of the effectiveness of its volatile organic compounds (VOCs) against a broad range of targets, this organism has been comprehensively studied and used as a biological control agent. Equipped with newly developed bioassays, cultivation and VOC collection techniques, the search has been broadened to include other endophytes that may have potential as biological control agents and potential fuel producers. It turns out that many of these fungi can be rapidly isolated using $M$. albus as a selection tool [9]. Some of the fungal endophytes making hydrocarbons and hydrocarbon derivatives that have been recently described include Gliocladium sp., Ascocoryne sarcodies, Phoma, and Hypoxylon sp. and the fungal products with fuel potential has been dubbed Mycodiesel ${ }^{\mathrm{Tu}}$ [9-15]. The fungal products with fuel potential have been dubbed Mycodiesel ${ }^{\mathrm{Tm}}$ [16]. Most interestingly, within the spectrum of volatile compounds being made by each of these endophytes, it is possible to find one or more volatile compounds commonly associated with the major classes of volatiles that are present in petroleum distillate fuels. These generally include the linear and branched chained alkanes, naphthenes (i.e. cyclalkanes e.g. cyclohexane), monoaromatics (benzene and derivatives), and polycyclic aromatics. In addition, these organisms also abundantly produce oxygenate disoprenoids including 1-butanol

*Corresponding author: Gary A Strobel, Department of Plant Sciences, Montana State University, Bozeman, Montana, 59717, USA, Tel: $\neg 1406994$ 5148; Fax $\neg 1$ 406994 7600; E-mail: uplgs@montana.edu

Received February 15, 2012; Accepted March 08, 2012; Published March 10, 2012

Citation: Mends MT, Yu E, Strobel GA, Riyaz-Ul-Hassan S, Booth E, et al. (2012) An Endophytic Nodulisporium sp. Producing Volatile Organic Compounds Having Bioactivity and Fuel Potential. J Pet Environ Biotechnol 3:117. doi:10.4172/2157 7463.1000117

Copyright: (C) 2012 Mends MT, et al. This is an open-access article distributed under the terms of the Creative Commons Attribution License, which permits unrestricted use, distribution, and reproduction in any medium, provided the original author and source are credited. 
-3- methyl-1-butanol, that hold promise as fuels or fuel additives. Other compounds have been discovered, not found in petroleum diesel but have potential as fuels including such monoterpenes as 1,8 cineole [9].

As fossil fuel sources are ever diminishing, the search for an alternative energy sources is becoming increasingly important. Ideally, such new sources should be renewable and compatible with existing engine infrastructure. In addition, any microorganism capable of converting biomass into hydrocarbon compatible fuels should be able to do so from biomass obtained from agricultural and other cellulosic wastes.

Thus, this report deals with the discovery of an endophytic fungus that produces highly desirable volatile metabolites. The endophytic fungus described in this report is Nodulisporium sp. having the most likely perfect stage being Daldinia eschscholzii (EC-12). It produces VOCs exhibiting moderate bioactivity against a wide range of plant pathogens as well as compounds identical or closely related to those found in diesel. This report also shows for the first time the application of a Carbotrap column technique enabling recovery of milligram amounts of fungal VOCs and the subsequent demonstration of their bioactivities [16]

\section{Methods and Materials}

\section{Isolating endophytes}

A search for new VOC producing endophytes was conducted in the Napo river region of the upper Amazon in Ecuador. At least 20 plants were obtained by clipping terminal stem pieces $(\mathrm{ca} .1 \times 20 \mathrm{~cm}$ ) from readily accessible portions of sample trees in a relatively small area of the jungle. The harvested specimens were kept cool and as soon as possible, the stems were surface treated and internal tissue pieces were set out on plates of water agar (WA) and glycerol-arginine medium (GAM) [9]. The tissue pieces were incubated at room temperature for several days. Visible fungal growth from the tissue samples were picked as hyphal tips and sub-cultured and transferred to potato dextrose agar (PDA) plates. An endophyte of interest was designated EC-12 and was obtained from a ca. $10 \mathrm{~m}$ tall leguminous tree-Myroxylon balsamum in the area of $\mathrm{S} 0.00^{\circ} 29^{\prime} 960$ and $\mathrm{W} 76^{\circ} 22^{\prime} 342$. This particular organism was not observed as an endophyte associated with any of the other plants that were sampled in this general area. The organism, EC-12, was stored at $-70^{\circ} \mathrm{C}$ as No. 2385 in the Mycological Collection of the Department of Plant Sciences at Montana State University. Long term storage of these rainforest endophytes is best done on doubly autoclaved, thoroughly wetted, and leached barley seeds.

\section{Scanning electron microscopy}

Scanning electron microscopy (SEM) was performed on EC-12 in order to acquire morphological data. The fungus was grown on $\gamma$-irradiated carnation leaves for 3 weeks and then the samples were slowly dehydrated in ethanol, critically point dried, coated with gold and examined with an FEI XL30 SEM - FEG with high vacuum mode using an Everhart-Thornley detector [9].

\section{ITS based phylogenetic analysis}

Phylogenetic analysis of EC-12 was carried out by the acquisition of the ITS-5.8 S ribosomal gene sequence. The fungus was grown on PDA for 7 days and DNA templates were prepared by using the Prepman Ultra Sample Preparation Reagent according to the manufacturer's guidelines (Applied Biosystems, USA). The
ITS regions of the fungus were amplified with the universal ITS primers ITS1 (5' TCCGTAGGTGAACCTGCGG $\left.3^{\prime}\right)$ and ITS4 (5' TCCTCCGCTTATTGATATGC $3^{\prime}$ ) using the polymerase chain reaction (PCR). The PCR conditions used were as follows: initial denaturation at $94^{\circ} \mathrm{C}$ for $3 \mathrm{~min}$ followed by 30 cycles of $94^{\circ} \mathrm{C}$ for 15 sec., $50 \mathrm{C}$ for $30 \mathrm{sec}$., $72^{\circ} \mathrm{C}$ for $45 \mathrm{sec}$., and a final extension at $72^{\circ} \mathrm{C}$ for 5 $\mathrm{min}$. The $50 \mu \mathrm{l}$ reaction mixture contained $1 \mathrm{x}$ PCR buffer, $200 \mu \mathrm{M}$ each dNTP, $1.5 \mathrm{mM} \mathrm{MgCl}$, 10 pmol of each primer, 1-5 ng of extracted DNA and $2.5 \mathrm{U}$ of Taq DNA polymerase. The amplified product (5 $\mu \mathrm{l})$ was visualized on $1 \%(\mathrm{w} / \mathrm{v})$ agarose gel to confirm the presence of a single amplified band. The amplified products were purified by Amicon Ultra columns (Millipore, USA) and 20-40 ng were used in a $10 \mu \mathrm{l}$ sequencing reaction using the Big Dye Terminator sequencing kit (v. 3.1), with 2 pmoles of the forward or the reverse primer in the cycle sequencing reaction. Twenty cycles of $96^{\circ} \mathrm{C}$ for $10 \mathrm{sec}, 50^{\circ} \mathrm{C}$ for $5 \mathrm{sec}$ and $60^{\circ} \mathrm{C}$ for $4 \mathrm{~min}$ were performed and the extension products were purified by ethanol precipitation, dissolved in $10 \mu \mathrm{l}$ of $\mathrm{HiDi}$ Formamide, incubated at $95^{\circ} \mathrm{C}$ for 1 min and loaded on ABI Prism 377 Genetic Analyzer (Perkin-Elmer, USA) for sequencing. All the reagents for sequencing were from Applied Biosystems, USA. The DNA sequence was aligned with the reference sequences in GenBank by BLASTN program [17]. Relevant sequences were downloaded and a phylogenetic tree was constructed according to Tamura et al. [18] The GenBank Accession number for the ITS sequence of this organism is - JQ424940.

\section{Carbotrap experiments}

In order to obtain quantitative weight measurements on the VOC production of this fungus and also to learn what VOCs are made under conditions of near optimum aeration, it was grown in $7 \mathrm{~L}$ of $\mathrm{PD}$ broth in a $10 \mathrm{~L}$ flask for 14 days, $200 \mathrm{rpm}$ at $22^{\circ} \mathrm{C}$. The culture had an inflow of compressed air at $800 \mathrm{ml} / \mathrm{min}$ per minute through a $20 \mu \mathrm{m}$ filter. The flask outlet was connected to a custom designed stainless steel column containing Carbotrap materials (Supelco-Carbotraps A and B) specifically designed for trapping hydrocarbons and hydrocarbon derivatives) for adsorption of the fungal culture VOCs starting at day 4 to the end of the fermentation period [16].

Eventually, the compounds in the Carbotrap column were desorbed by heating in a programmable oven, purged with a flow of nitrogen gas, followed by passage of the effluent in a tube cooled with liquid nitrogen [16]. Gravimetric analysis provided information on VOC yields. The efficiency of the column trapping method ranges from $65-70 \%$. In addition, the gas trapping vial, having a septum, was gently warmed and thus directly prepared for qualitative GC/MS gas analysis. The trapped liquid compounds were also used in bioassay tests. The dry weight of the fungal mass was determined after centrifugation and drying of the insolubles found at the end of the incubation period.

\section{Bioactivities of EC-12}

The volatiles produced by a 13 day old culture (optimum time) of EC-12 were tested for antimicrobial activity against selected pathogenic fungi according to a VOC bioassay test system previously described for analysis of VOCs produced by Muscodor albus [19]. The assays were conducted by growing the test organism on one side (half moon) of a Petri plate (on PDA) and then placing a small plug of each test fungus (a $3 \mathrm{~mm}$ plug) on the opposite side of the plate (half moon) of a PDA plate. The plate was then wrapped with Parafilm and incubated at $23^{\circ} \mathrm{C}$ for varying time periods. Growth of the filamentous test fungi 
Citation: Mends MT, Yu E, Strobel GA, Riyaz-UI-Hassan S, Booth E, et al. (2012) An Endophytic Nodulisporium sp. Producing Volatile Organic Compounds Having Bioactivity and Fuel Potential. J Pet Environ Biotechnol 3:117. doi:10.4172/2157-7463.1000117

was quantitatively assessed by making multiple measurements of growth extending from the edge of the inoculum plugs comparable to corresponding controls after several days as described previously by Strobel et al. [19]. On the other hand, the Carbotrapped VOCs were recovered from the trapping tube and assayed according to the methods described by Strobel when testing the artificial mixtures of VOCs produced by $M$. albus [19]. The test mixture is transferred to a small plastic cup and placed in the center of a Petri plate (PDA) surrounded by small plugs of test organisms and the growth of the test organisms measured after appropriate exposure times. All test organisms were obtained from the Mycological Collection, Department of Plant Sciences, Montana State University.

\section{GC/MS analyses}

In order to determine the composition of the VOCs under microaerophilic conditions, the fungus was grown in $60 \mathrm{ml}$ of PD broth for 7 days in a sealed $250 \mathrm{ml}$ Erylenmeyer flask, with constant agitation at $22^{\circ} \mathrm{C}$. The volatiles were sampled from the headspace of the fungal cultures after days. Briefly, a small hole was drilled in the cap and a preconditioned "Solid Phase Micro Extraction (SPME) fiber" coated with DVB/CAR/PDMS was inserted and the fiber exposed for $5 \mathrm{~min}$. The VOCs bound to the fiber were desorbed for $3 \mathrm{~min}$ in a split-/splitless injector (splitless mode, $250^{\circ} \mathrm{C}$ ) of a Varian 3800 gas chromatograph coupled with an ion trap mass spectrometer attached to a DB5-HT (30

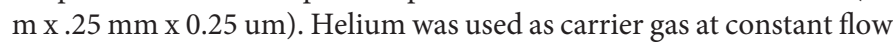
rate $1 \mathrm{ml} / \mathrm{min}$. The oven program was $30^{\circ} \mathrm{C}$ (hold $3 \mathrm{~min}$ ), $5 \mathrm{C} / \mathrm{min}$ to $220^{\circ} \mathrm{C}, 10 \mathrm{C} / \mathrm{min}$ to $250^{\circ} \mathrm{C}$ (hold $5 \mathrm{~min}$ ). The MSD parameters were EI at $70 \mathrm{eV}$, mass range was $30-500 \mathrm{Da}$, and the scan speed was $2 \mathrm{scans} / \mathrm{sec}$. Headspace SPME-GC/MS was performed on replicate EC-12 PD broth as well as $\mathrm{PD}$ agar cultures.

Qualitative gas analysis of the compounds desorbed from the stainless steel Carbotrap (trapping tube) was done on a preconditioned 50/30DVB/CAR/PDMSSPME fiber for $5 \mathrm{~min}$ after the tube was gently warmed to volatilize the trapped liquid [16]. The syringe was then inserted into the splitless injection port of a Hewlett Packard 6890 gas chromatograph containing a $30 \mathrm{~m} \times 0.25 \mathrm{~mm}$ I.D. ZB Wax capillary column with a film thickness of $0.50 \mu \mathrm{m}$. The column was temperature programmed as follows: $30^{\circ} \mathrm{C}$ for $2 \mathrm{~min}$ increased to $220^{\circ} \mathrm{C}$ at $5^{\circ} \mathrm{C} \mathrm{min}$ ${ }^{1}$. The carrier gas was ultra high purity helium, and the initial column head pressure was $50 \mathrm{kPa}$. A $30 \mathrm{sec}$ injection time was used to introduce the sample fiber into the GC. The gas chromatograph was interfaced to a Hewlett Packard 5973 mass selective detector (mass spectrometer) operating at unit resolution. The MS was scanned at a rate of 2.5 scans per second over a mass range of 35-360 amu. Data acquisition and data processing were performed on the Hewlett Packard ChemStation software system.

In all cases, tentative identification of the fungal compounds was made via library comparison using the NIST 2011 (US- National Institute of Standards and Technology) mass spectral library and all chemical compounds described in this report use the NIST data base chemical terminology. Only compounds, having a quality match score better than $70 \%$, are listed and described in this report. Peak areas for all other unidentified compounds were lumped and summed for each EC-12 culture tested. Compounds appearing in the control flasks, plates, or tubes were removed from the analysis.

\section{Results and Discussion}

The endophytic organism EC-12, by light and scanning electron microscopy produced an imperfect stage resembling that of Nodulisporium sp. (Figure 1). The organism when grown on PDA (2 week old culture) produced whitish felt-like mycelia on the $4 \mathrm{~cm}$ perphery of the culture. On the other hand, the center of the culture was a distinctively greyish/brown coloration. The reverse side of the plate, after 2 weeks, was totally brownish/black. The mycelium produced erect to suberect, branching conidiophores with slender conidiogenous cells attached in irregular to verticillate patterns. Conidiogenous cells terminated in clusters of one-celled conidia at the apical end. The conidia $(1.81 \pm 0.6 \times 3.75 \pm 0.3 \mu \mathrm{m})$, as viewed by SEM, were clavateellipsoid with truncated ends, but by regular light microscopy they appeared more ellipsoidal. Evidence of successional budding was seen as bud scars on conidiogenous cells (Figure 1). In all respects the fungus totally resembled Nodulisporium sp., [20]. However, the18S-ITS$5.8 \mathrm{~S}$ of the organism showed $99 \%$ sequence similarity with Daldinia escholzii which is the most likely the perfect stage for this organism even though it was never observed and D. escholzii has Nodulisporium sp. as its imperfect stage [20] (Figure 2). Multiple substrates were tested for varying lengths of time in order to observe the perfect stage but to no avail

\section{Composition of the VOCs produced by Nodulisporium sp.}

When Nodulisporium sp. was originally isolated, a 7-10 day old culture possessed a distinctive but pleasant odor. This observation

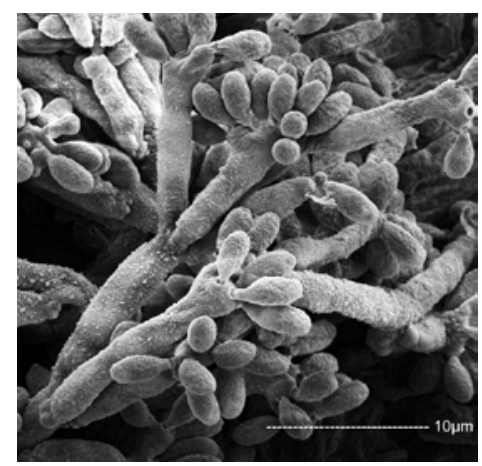

Figure 1: The Nodulisporium sp. or imperfect stage of EC-12 (Nodulisporium sp.) as seen by SEM. Note the conidiophores bearing numerous conidia.

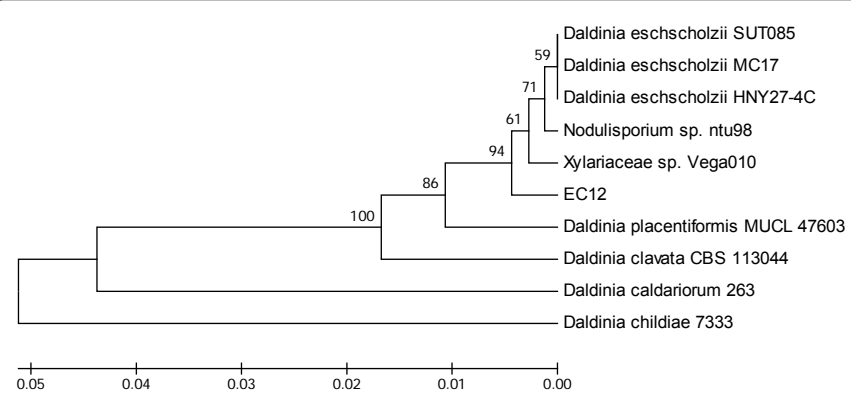

Figure 2: A Phylogenetic tree, depicting the evolutionary position of the endophyte EC12, was constructed using the UPGMA method [11]. The percentage of replicate trees in which the associated taxa clustered together in the bootstrap test (500 replicates) is shown next to the branches [5]. The tree is drawn to scale, with branch lengths in the same units as those of the evolutionary distances used to infer the phylogenetic tree. The evolutionary distances were computed using the Maximum Composite Likelihood method according to Tamara et al. [17] and are in the units of the number of base substitutions per site. All positions containing gaps and missing data were eliminated from the dataset (Complete deletion option). 
Citation: Mends MT, Yu E, Strobel GA, Riyaz-UI-Hassan S, Booth E, et al. (2012) An Endophytic Nodulisporium sp. Producing Volatile Organic Compounds Having Bioactivity and Fuel Potential. J Pet Environ Biotechnol 3:117. doi:10.4172/2157-7463.1000117

Page 4 of 7

necessitated a closer chemical identification of the VOCs being made by this organism under varying conditions of growth. The potential fuel compounds that could be consistently matched, in repeated experiments and on a qualitative basis, were 1,4-cyclohexadiene, 1-methyl-, 1-4 pentadiene and cyclohexene, 1-methyl-4-(1-methylethenyl)-, but other volatile compounds of interest were also produced (Table 1). However, the quantities of individual components in three separate analyses, using the SPME fiber technique, were not greatly consistent due to the inherent limitations of the SPME fiber technique but qualitatively they were almost identical (Table 1). Interestingly, the cyclohexanes as well as pentane and its derivatives constitute some of the major groups of hydrocarbons in diesel fuels as analyzed by the SPME technique (Strobel, unpublished). However, the compounds in greatest abundance in the fungal VOCs were 1-butanol-3 methyl (and or 1 pentanol), and phenylethyl alcohol which also have fuel potential (Table 1). Also, present in the analysis were a series of terpenoids including naphthene and azulene derivatives (Table 1). Similar data were obtained when SPME analyses were conducted on Nodulisporium sp. grown on PDA plates. However, differences were noted only in the relative amounts of the VOCs that were detected. It is to be noted that many of the VOCs in the mixture could not have their identities assigned since the percentage match was low. This may be the result of low concentrations of compounds present (detection limits) and/or perhaps interference with high amounts of other compounds. Further serial transfers of the organism resulted in a change of odor as well as detectable changes in the production of VOCs (data not shown).

In both SPME analyses of plate and liquid culture analyses there were limited detectable numbers of VOCs produced by Nodulisporium sp. This may be the result of sampling being done in only a short time frame and scale. Thus, in order to get a more complete picture of what the potential might be for this fungus to make fuel potential compounds, a $10 \mathrm{~L}$ flask equipped with a stainless steel column having Carbotrap materials $A \& B$ was attached to the outflow of the flask for the majority of the incubation period. The hydrocarbons and related compounds were desorbed from the Carbotrap materials and collected in a cooled tube (liquid nitrogen). The amount of material collected was $19.0 \mathrm{mg}$.

The SPME-GC/MS analysis of the VOCs trapped by the Carbotraps yielded a plethora of hydrocarbon derivatives (Table 2). Again, the most abundant substances detected were phenylethyl alcohol and 1-butanol-3-methyl which is comparable to that found in the smaller flasks (Table 2). Also, it appears that the most, but not all of the compounds present in the trapping tube could detected and identified by this method (Table 2). Thus, the increased numbers of VOCs in the Carbotrapped compounds is likely related to the increased amounts of each component. Most interestingly, in the analyses, was the presence of a complete series of straight chained alkyl alcohols starting with 1- pentanol through 1-nonanol. Hydrocarbon components such as tridecane and tetradecane along with various methylated benzenes were found in this analysis (Table 2). A clear common theme in analysis of the mixture is the presence of a series of alkyl esters of small molecular weight carboxylic acids, especially butanoic and hexanoic acids, as well as a series of alkyl ketones including 4 -nonanone and 3-hepten2-one. Interestingly, none of the terpenoids and the oxime produced by the fungus in the microaerophilic environment was present in the large flask (Tables1 and 2). However one sesquiterpenoid (caryophyl-

\begin{tabular}{|c|c|c|c|c|c|c|}
\hline $\begin{array}{l}\text { Retention } \\
\text { Time (min) }\end{array}$ & *\% Area-PD1 & $\%$ Area-PD2 & $\%$ Area-PD3 & Possible Compound & $\begin{array}{c}\text { Molecular } \\
\text { Weight }(\mathrm{g} / \mathrm{mol})\end{array}$ & $\begin{array}{l}\text { Quality } \\
\text { Match }\end{array}$ \\
\hline 5.4 & 26 & 18.7 & 17.4 & 1-Pentanol or 1-Butanol, 3-methyl- & 88 & 72 \\
\hline 6.6 & 1 & 28.3 & 32.8 & 1,4-Cyclohexadiene, 1-methyl- & 94 & 91 \\
\hline 10.6 & 21 & 2 & 0.5 & Oxime-, methoxy-phenyl-_ & 151 & 82 \\
\hline 11.1 & 1.7 & 6 & 10 & 1,4-Pentadiene & 68 & 77 \\
\hline 14.9 & nd & 1.9 & 1.4 & Cyclohexene, 1-methyl-4-(1-methylethenyl)- & 136 & 85 \\
\hline 15.1 & 0.6 & nd & 0.7 & Eucalyptol & 154 & 79 \\
\hline 16.5 & nd & 1.4 & 0.8 & 3-Heptanone, 5-ethyl-4-methyl- & 156 & 75 \\
\hline 17.6 & 14.3 & 8.9 & 9.3 & Phenylethyl Alcohol & 122 & 94 \\
\hline 21.1 & nd & 0.3 & 0.2 & Benzothiazole & 135 & 91 \\
\hline 25.5 & 1.6 & 1.1 & 2.3 & $\beta$-Elemene & 204 & 83 \\
\hline 26.7 & 1 & 1 & 1.1 & a-Guaiene & 204 & 86 \\
\hline 27.7 & 5.6 & 7.8 & 3.4 & 2H-1-Benzopyran-2-one, 4,7-dihydroxy- & 178 & 76 \\
\hline 28.1 & 0.7 & 0.3 & 0.5 & Chamigrene & 204 & 75 \\
\hline 28.4 & 4 & 2.6 & 4.9 & $\begin{array}{l}\text { Azulene, 1,2,3,5,6,7,8,8a-octahydro-1,4-dimethyl-7-(1-methylethenyl)- } \\
\text { (aka Guaia-1(10)-11-diene) }\end{array}$ & 204 & 85 \\
\hline 32 & 11.5 & 1.9 & 2 & $\begin{array}{l}\text { Azulene, 1,2,3,3a,4,5,6,7-octahydro-1,4-dimethyl-7-(1-methylethenyl)- ( } \\
\text { aka y-Gurjunene) }\end{array}$ & 204 & 84 \\
\hline 32.1 & nd & nd & 4.8 & 2-Naphthalenol, 3-methoxy- & 174 & 73 \\
\hline- & 11.3 & 17.9 & 7.9 & Remaining unknown compounds & - & $<70$ \\
\hline
\end{tabular}

*\% Area is given as the area of the peak of interest over total area of peaks in chromatogram (from 3 replicate EC-12 cultures grown in potato dextrose ( PD1-PD3)). Only compounds with quality match scores $>70$ are listed. Area of unassigned peaks are summed and listed as unknown compounds. Compounds also observed in PD broth control are italicized, $(\mathrm{nd})=$ not detected. Details of VOC extraction and GC/MS analysis are in Methods section.

Table 1: The VOC composition of Nodulisporium sp. flask analyzed at 7 days of growth by Headspace SPME-GC/MS on three different cultures each grown on PD broth. The mycelial dry weight per culture is ca. $0.2 \mathrm{~g}$. 
Citation: Mends MT, Yu E, Strobel GA, Riyaz-Ul-Hassan S, Booth E, et al. (2012) An Endophytic Nodulisporium sp. Producing Volatile Organic Compounds Having Bioactivity and Fuel Potential. J Pet Environ Biotechnol 3:117. doi:10.4172/2157-7463.1000117

Page 5 of 7

\begin{tabular}{|c|c|c|c|c|}
\hline Retention Time (min) & $\begin{array}{c}\text { Relative } \\
\text { Abundance }\end{array}$ & Possible Compound & $\begin{array}{l}\text { Molecular } \\
\text { Weight }\end{array}$ & Quality \\
\hline 6.44 & 0.212 & Heptane, 5-ethyl-2,2,3-trimethyl- & 170 & 78 \\
\hline 8.06 & 0.353 & Tetradecane & 198 & 90 \\
\hline 8.34 & 0.337 & 1-Propanol, 2-methyl- & 74 & 80 \\
\hline 9.14 & 2.430 & 1-Butanol, 3-methyl, acetate & 130 & 86 \\
\hline 9.21 & 0.480 & 4-Heptanone & 114 & 78 \\
\hline 10.13 & 1.938 & Butanoic acid, 2-methylpropyl ester & 144 & 90 \\
\hline 11.07 & 0.347 & Tridecane & 184 & 86 \\
\hline 11.78 & 32.624 & 1-Butanol, 3-methyl- & 88 & 83 \\
\hline 11.92 & 0.194 & Butanoic acid, butyl ester & 144 & 72 \\
\hline 12.08 & 0.195 & Benzene, 1-ethyl-3-methyl- & 120 & 80 \\
\hline 12.29 & 0.896 & Hexanoic acid, ethyl ester & 144 & 97 \\
\hline 12.66 & 0.200 & Benzene, 1,2,4-trimethyl- & 120 & 95 \\
\hline 12.77 & 0.265 & 1-Pentanol & 88 & 83 \\
\hline 13.17 & 5.047 & Butanoic acid, 3-methylbutyl ester & 158 & 90 \\
\hline 13.31 & 0.823 & 4-Hexen-3-one, 4-methyl- & 112 & 90 \\
\hline 14.24 & 0.631 & 3-Hepten-2-one, (Z)- & 112 & 80 \\
\hline 14.54 & 0.258 & 1-Pentanol, 4-methyl- & 102 & 72 \\
\hline 14.64 & 0.254 & 2-Heptanol & 116 & 83 \\
\hline 14.86 & 1.614 & 4-Nonanone & 142 & 91 \\
\hline 15.61 & 2.355 & 1-Hexanol & 102 & 83 \\
\hline 15.85 & 0.191 & Benzene, 1,2,4,5-tetramethyl- & 134 & 76 \\
\hline 17.02 & 3.139 & 3-(1-Methylpropyl)-2-hydroxy-2-cyclopenten-1-one & 154 & 72 \\
\hline 17.17 & 1.784 & 1-Nonanol & 144 & 72 \\
\hline 18.17 & 0.395 & 1-Octen-3-ol & 128 & 72 \\
\hline 18.30 & 0.770 & Heptanol & 116 & 90 \\
\hline 18.53 & 3.135 & dl-6-Methyl-5-hepten-2-ol & 128 & 95 \\
\hline 18.86 & 0.239 & 4-Nonanol & 144 & 86 \\
\hline 19.80 & 0.368 & 2,4-Heptandienal, 2,4-dimethyl- & 138 & 72 \\
\hline 20.06 & 0.261 & Bicyclo[2.2.1]heptan-2-one, 1,7,7-trimethyl-, (1R)- & 152 & 97 \\
\hline 20.63 & 0.255 & 2,3-Butanediol & 90 & 80 \\
\hline 20.91 & 1.805 & 1-Octanol & 130 & 91 \\
\hline 21.54 & 0.681 & 2,3-Butanediol, [R-( $\left.\left(\mathrm{R}^{*}, \mathrm{R}^{*}\right)\right]-$ & 90 & 86 \\
\hline 21.71 & 1.653 & 1,5-Cyclodecadiene, 1,5-dimethyl-8-(1-methylethylidene)-, (e,e)- & 204 & 90 \\
\hline 21.91 & 0.287 & Caryophyllene & 204 & 99 \\
\hline 22.36 & 0.215 & Cycloprop[a]indene, 1,1a,6,6a-tetrahydro- & 130 & 95 \\
\hline 25.82 & 0.257 & Benzenemethanol, .alpha.,.alpha.-dimethyl- & 136 & 90 \\
\hline 26.51 & 0.254 & Acetic acid, 2-phenylethyl ester & 164 & 83 \\
\hline 27.08 & 0.593 & Acetic acid, 2-phenylethyl ester & 164 & 90 \\
\hline 28.48 & 0.204 & Benzyl Alcohol & 108 & 98 \\
\hline 29.33 & 30.999 & Phenylethyl Alcohol & 122 & 93 \\
\hline 30.24 & 0.193 & Benzothiazole & 135 & 81 \\
\hline- & 44.924 & Remaining unknown compounds & - & $<70$ \\
\hline Overall Abundance & 144.056 & & & \\
\hline
\end{tabular}

Table 2: GC/MS for liquid collected from the Carbotrap extraction of Nodulisporium sp. produced by $21.5 \mathrm{~g}$ dry weight of fungal hyphae over a 2 week period. The details of the fermentation and extraction techniques are in Methods. 
Citation: Mends MT, Yu E, Strobel GA, Riyaz-UI-Hassan S, Booth E, et al. (2012) An Endophytic Nodulisporium sp. Producing Volatile Organic Compounds Having Bioactivity and Fuel Potential. J Pet Environ Biotechnol 3:117. doi:10.4172/2157-7463.1000117

Page 6 of 7

lene) was present but was not found in the smaller fermentation flasks (Tables 1 and 2). In addition, also absent in the large flask were the cyclohexene and cyclohexadiene derivatives (Tables 1 and 2), but several highly branched hydrocarbons were noted including heptane, 5-ethyl2,2,3-trimethyl- and a cyclodecadiene derivative (Table 2). The incorporation of nitrogen and sulfur into the VOC stream (via such compounds as oximes and thiazoles) is undesirable for fuel use. Therefore, overall, it appears that almost the entire mixture of VOCs produced by this fungus has fuel potential. Future work will focus on tailoring the scope of the VOC stream for particular combustion applications.

\section{Biological activities of the VOCs of Nodulisporium sp.}

Since Nodulisporium sp. was making a plethora of VOCs it was deemed important to determine the biological role of these gases. A simple split plate test was done on 13 day old cultures of Nodulisporium sp. The results showed that the VOCs of the fungus were active against a wide range of plant pathogenic fungi (Table 3). Rhizoctonia solani and A. flavus were most sensitive to the VOCs of Nodulisporium sp. with death resulting for only a $48 \mathrm{hr}$ exposure time (Table 3). Both Phytophthora spp. as well as S. sclerotiorum were also sensitive to the VOCs but were not killed by them. However, others including $P$. ultimum, $V$. dahliae and $F$. solani were unaffected during the time course of the experiment (Table 3). This is in sharp contrast to the sensitivities of these same fungi to the VOCs of M.albus where in $P$. ultimum and the Phytophthora spp. are some of the most sensitive fungi to these volatiles [19]. This suggests that the chemistry of the volatiles is different and that there are different targets within the test fungi for sensitivity to various VOCs. This is probably the case since many of the VOCs reported for M.albus are not present in Nodulisporium sp. and vice versa (Tables 1 and 2) [19].

Finally, since the VOCs of Nodulisporium sp. could be recovered by the Carbotrap technology, they too were subjected to a bioassay test utilizing several select plant pathogens (Table 4). A small amount (0.4

\begin{tabular}{|l|c|c|c|}
\hline Test Organism & \multicolumn{2}{|c|}{ Percent Inhibition } & $\begin{array}{c}\text { Dead (D) or Alive } \\
\text { (A) }\end{array}$ \\
\hline Aspergillus flavus & $100.0 \%$ & \pm 0.00 & $\mathrm{D}$ \\
\hline Botrytis cinerea & $27.1 \%$ & \pm 0.49 & $\mathrm{~A}$ \\
\hline Colletotrichum lagenarium & $39.9 \%$ & \pm 0.20 & $\mathrm{~A}$ \\
\hline Ceratocystis ulmi & $23.8 \%$ & \pm 0.03 & $\mathrm{~A}$ \\
\hline Cercospora beticola & $10.8 \%$ & \pm 0.10 & $\mathrm{~A}$ \\
\hline Fusarium solani & $-0.4 \%$ & \pm 0.06 & $\mathrm{~A}$ \\
\hline Geotrichum candidum & $-7.1 \%$ & \pm 0.01 & $\mathrm{~A}$ \\
\hline Phytophthora palmivora & $56.9 \%$ & \pm 0.18 & $\mathrm{~A}$ \\
\hline Phytophthora cinnamoni & $73.4 \%$ & \pm 0.04 & $\mathrm{~A}$ \\
\hline Pythium ultimum & $-4.4 \%$ & \pm 0.15 & $\mathrm{~A}$ \\
\hline Rhizoctonia solani & $100.0 \%$ & \pm 0.00 & $\mathrm{D}$ \\
\hline Sclerotinia sclerotiorum & $79.2 \%$ & \pm 0.18 & $\mathrm{~A}$ \\
\hline Trichoderma viridae & $47.7 \%$ & \pm 0.67 & $\mathrm{~A}$ \\
\hline Verticillium dahliae & $-12.7 \%$ & \pm 0.04 & $\mathrm{~A}$ \\
\hline Table & & & \\
\hline
\end{tabular}

Table 3: Effects of a 13-day-old colony of Nodulisporium sp. on various fungi in a simple split plate test. Viability was measured after $48 \mathrm{hr}$ of exposure to the fungal VOCs. Inhibition was measured after a $48 \mathrm{hr}$ exposure to the Nodulisporium sp. vOCs.

\begin{tabular}{|l|c|c|}
\hline \multicolumn{1}{|c|}{ Test Organism } & $\%$ Inhibition & Dead (D) or Alive (A) \\
\hline Aspergillus fumigatus & $3.4 \% \pm 0.02$ & $\mathrm{~A}$ \\
\hline Geotrichum candidum & $4.6 \% \pm 0.02$ & $\mathrm{~A}$ \\
\hline Phytophthora cinnamomi & $-29.6 \% \pm 0.12$ & $\mathrm{~A}$ \\
\hline Rhizoctonia solani & $21.2 \% \pm 0.10$ & $\mathrm{~A}$ \\
\hline Sclerotinia sclerotiorum & $5.2 \% \pm 0.24$ & $\mathrm{~A}$ \\
\hline Verticillium dahliae & $-8.4 \% \pm 0.09$ & $\mathrm{~A}$ \\
\hline
\end{tabular}

Table 4: Effects of liquid volatile compounds collected from a 13-day-old colony of Nodulisporium sp. on various fungi as conducted in a well assay on a Petri plate with PDA.

$\mathrm{mg}$ ) of the collected VOCs of Nodulisporium sp., in the form of a liquid, when placed in the plastic cup assay system, as described in Methods, produced some inhibition of the same target organisms as observed in the inhibition experiments with Nodulisporium sp. itself (Table 3).

Namely, the liquid mixture yielded the greatest inhibition response from R.solani and S. sclerotiorum but with somewhat mixed results from the other test organisms (Table 4). This seems to be the first report where by fungal VOCs have been trapped and reconstituted in bioassay tests. The decrease in the relative bioactivity may be related to the small amount of materials tested, a loss of one or more critical bioactivity compounds, or the lability of certain components that are necessary for bioactivity.

\section{Conclusions}

The fungal isolate used in this study was obtained as an endophyte from the upper Amazon basin. The organism, by virtue of its molecular sequence data and its morphology best fits the description of a Nodulisporium sp. with a Daldinia sp. as its most likely perfect stage (Figures 1 and 2). This isolate of Nodulisporium sp. produces a series of VOCs many of which are hydrocarbons or hydrocarbon derivatives (Tables 1 and 2). The composition of VOCs seems to be related to the conditions under which the fungus is grown (Tables 1 and 2). For instance, the cyclohexene derivatives are consistently produced when the organism has been grown on a solid medium or under microaerophilic conditions (Table 1). The organism, when grown on PD broth in a larger scale and under continuous aeration produced a plethora of alkyl alcohols, esters, and ketones (Table 2). These compounds by themselves, with a few exceptions, are potential fuels and further work on optimizing production should be pursued.

It is to be noted in this study, that in both types of fermentation, representative VOCs were produced in each that perfectly or closely match each of the major classes of molecules found in petroleum distillate (diesel) (Tables 1 and 2). In some cases, the specific VOC may be only one or two reductive steps away from the product actually found in diesel such as the cyclohexenes or the series of alkyl alcohols or acids (Table 1 and 2). Thus, previously it had not gone unrecognized that endophytic fungi such as Hypoxylon sp. may have contributed to the breakdown of plant materials on the ancient earth with the subsequent entrapment of the fungal products by certain components of the earth such as shale which has been experimentally demonstrated [16]. It is surmised that heat and the reductive conditions found in the earth could have been responsible for further conversion of the more oxidized fungal products (i.e. alkyl alcohols and acids) to the 
Citation: Mends MT, Yu E, Strobel GA, Riyaz-UI-Hassan S, Booth E, et al. (2012) An Endophytic Nodulisporium sp. Producing Volatile Organic Compounds Having Bioactivity and Fuel Potential. J Pet Environ Biotechnol 3:117. doi:10.4172/2157-7463.1000117

more reduced alkanes. It is proposed that these endophytes began the processes of plant tissue degradation at the time the host plant died since they are they represent the microbial community being the first to have access to the dead plant tissues [14]. Presently, there is a growing list of endophytic fungi making hydrocarbons and hydrocarbon derivatives [9-15].

The biological activity of the VOCs of this fungus is quite interesting given the fact that it expresses so much selectively (Table 3). For instance, a 2 day exposure to the gases of Nodulisporium sp. resulted in the death of both A.fumigatus as well as $R$. solani. The former is an as comycete and the latter is a basidiomycete. And although many other fungi were inhibited by the VOCs, there were a few in which there was no inhibition whatsoever and these include such fungi as F.solani and P.ultimum. Also, quite important is the observation that the collected and tested VOCs of the Nodulisporium sp. somewhat mimicked the activity of the actual fungus (Table 4). It would appear that this kind of testing should be done in future studies involving fungi making biologically active VOCs.

\section{Acknowledgements}

The authors would like to thank Dr Blake Simmons for helpful discussion during the course of this study. The authors acknowledge the supported by the National Science Foundation (NSF) Emerging Frontiers in Research and Innovation (EFRI), Grant No. 0937613 to Dr. Brent Peyton of Montana State University). This work is supported by the Laboratory Directed Research and Development (LDRD) program at Sandia National Laboratories, a multiprogram laboratory operated by Sandia Corporation, a Lockheed Martin Company, for the United States Department of Energy's National Nuclear Security Administration under contract DE-AC04-94AL85000.

\section{References}

1. Bacon CW, White JF (2000) Microbial Endophytes. Marcel Dekker Inc., N.Y.

2. Smith SA, Tank DC, Boulanger LA, Bascom-Slack CA, Eisenman K, et al. (2008) Bioactive endophytes support intensified exploration and conservation PloS 1 Biology. PLoS One 3: e3052.

3. Strobel GA, Daisy B (2003) Bioprospecting for microbial endophytes and their natural products. Microbiol Mol Biol Rev 67: 491-502.

4. Verma VC, Kharwar RN, Strobel GA (2009) Chemical and functional diversity of natural products from plant associated endophytic fungi. Nat Prod Commun 4: 1511-1532

5. Strobel G (2006) Harnessing endophytes for industrial microbiology. Curr Opin Microbiol 9: 240-244.

6. Yuan ZL, Su ZZ, Mao LJ, Peng YQ, Yang GM, et al. (2011) Distinctive endophytic fungal assemblage in stems of wild rice (Oryzagranulata) in china with special reference to two species of Muscodor (xylariaceae). Journal of Microbiology 49: 15-23

7. Yuan ZL, Rao LB, Chen YC, Zhang CL, Wu YG (2011) From pattern to process: species and functional diversity in fungal endophytes of Abiesbeshanzuensis. Fungal Biol 115: 197-213.

8. Zhang CL, Wang GP, Mao LJ, Komon-Zelazowska M, Yuan ZL, et al. (2010) Muscodorfengyangensis sp. nov.from southeast China: morphology, physiology and production of volatile compounds. Fungal Biol 114: 797-808.

9. Tomsheck AR, Strobel GA, Booth E, Geary B, Spakowicz D, et al. (2010) Hypoxylon sp. an endophyte of Perseaindica, producing 1, 8- cineole and other bioactive volatiles with fuel potential. Microb Ecol 60: 903-914.

10. Ahamed A, Ahring BK (2011) Production of hydrocarbon compounds by endophytic fungi Gliocaldium sp. grown on cellulose. Bioresour Technol 102: 9718-9722.

11. Griffin MA, Spakowicz DJ, Gianoulis TA, Strobel SA (2010) Volatile organic compoundproduction by organisms in the genus Ascocoryne and a reevaluation of myco-diesel production by NRRL 50072. Microbiology 156 3814-3829.

12. Ul-Hassan SR, Strobel GA, Booth E, Knighton B, Floerchinger C, et al (2012) Modulation of Volatile Organic Compound Formation in theMycodiese producing endophyte-Hypoxylonsp C1-4. Microbiology 158: 465-473.

13. Singh SK, Strobel GA, Knighton B, Geary B, Sears J, et al. (2010) An endophytic Phomopsis sp. possessing bioactivity and fuel potential with its volatile organic compounds. Microbial Ecol 61: 729-739.

14. Strobel GA, Knighton B, Kluck K, Ren Y, Livinghouse T, et al. (2008) The production of myco-diesel hydrocarbons and their derivatives by the endophytic fungus Gliocladium roseum (NRRL 50072). Microbiology 154: 3319-3328.

15. Strobel G, Singh SK, Riyaz-Ul-Hassan S, Mitchel AM, Geary B, et al. (2011) An endophytic/pathogenic Phoma sp. from creosote bush producing biologically active volatile compounds having fuel potential. FEMS Microbiol Lett 320 : 87-94.

16. Booth E, Strobel G, Knighton B, Sears J, Geary B, et al. (2011) A rapid column technique for trapping and collecting volatile fungal hydrocarbons. Biotechno Lett 33: 1963-1972.

17. Altschul SF, Madden TL, Schaffer AA, Zhang J, Zhang Z, et al. (1997) Gapped BLAST and PSI-BLAST: a new generation of protein database search programs. Nucleic Acids Res 25: 3389-3402.

18. Tamura K, Dudley J, Nei M, Kumar S (2007) MEGA4: Molecular Evolutionary Genetics Analysis (MEGA) software version 4.0. Mol Biol Evol 24: 1596-1599.

19. Strobel GA, Dirksie E, Sears J, Markworth C (2001) Volatile antimicrobials from a novel endophytic fungus. Microbiology 147: 2943-2950.

20. Hanlin RT (1997) Illustrated Genera of Ascomycetes. Am Phytopath Press, St Paul, Mn.

21. Felsenstein J (1985) Confidence limits on phylogenies: An approach using the bootstrap. Evolution 39: 783-791.

22. Tamura K, Nei M, Kumar S (2004) Prospects for inferring very large phylogenies by using the neighbor-joining method. Proc Natl Acad Sci U S A 101: 1103011035.

23. Sneath PHA, Sokal RR (1973) Numerical Taxonomy. Freeman, San Francisco. 